\title{
An audit of MTP in women with high-risk pregnancy
}

\author{
Deepali Srivastava ${ }^{1}$, Sandeepa Srivastava ${ }^{2}$, Pratibha Kumari ${ }^{3}$, Deepanshi Srivastava ${ }^{4}$ \\ 1//C Post Partum Unit, Department of Obstetrics and Gynaecology, King George's Medical University, ${ }^{2}$ Senior \\ Consultant Gynaecologist, Department of Obstetrics and Gynaecology, Lok Bandhu Raj Narayan Combined Hospital, \\ ${ }^{3} \mathrm{PhD}$, Department of Obstetrics and Gynaecology, King George's Medical University, Lucknow, Uttar Pradesh, India, \\ ${ }^{4}$ Technical Assistant, B.Tech, SRM Institute of Technology, Chennai, Tamil Nadu, India
}

Background: The women who have been pregnant more than four times are fewer than 18 or over 35-years-old, or have at least one medical issue before or during pregnancy, the pregnancy is considered high-risk. Increased maternal and foetal mortality and morbidity are linked to these risk factors. MTP in itself is a blind and risky procedure and performing it in High Risk Pregnancy (HRP) is a challenge for obstetrics and gynecology personnel. When performed with all pre, intra and post-op precautions, results are good and patient-friendly. Aims and Objectives: Aims of the study were to calculate the number, high-risk factors, method used, and its outcome of MTP in HRP. Materials and Methods: The present study was a retrospective observational study done at $\mathrm{QMH}, \mathrm{KGMU}$, Lucknow performed on subjects admitted for MTP from January 2018 to December 2018. Total admitted patients seeking MTP were 450 out of which 93 belonged to High-Risk Group who underwent surgical and medical abortion accordingly. All precautions and norms defined by Govt. of India were taken care of. Cases were evaluated on the basis of high-risk factors- Age, parity, obstetrical and medical illnesses, and interval since last delivery. Results: Out of 93 high-risk cases, 88 cases were of $1^{\text {st }}$ trimester and 5 were of $2^{\text {nd }}$ trimester abortion. Six cases required suction evacuation while seven cases were managed medically using medical abortion kit. Contraception was given to all subjects according to their needs. Seventy-one women were of more than $35 \mathrm{yrs}$, while two were teenagers. 21 women were grand multipara. Women of obstetrical risk were 17 while the rest were having medical illnesses. Conclusion: This study concludes that there are a large number of high-risk groups for MTP again showing unmet need and lack of specialized counseling of HR patients according to their mental and physical condition. Early recognition of pregnancy and timely intervention can be lifesaving in these women and proper contraceptive counseling is required to prevent future pregnancies.

Key words: Abortion; Contraceptions; Foetal mortality; High-risk pregnancies; MTP
Access this article online

Website:

http://nepjol.info/index.php/AJMS DOI: $10.3126 / a j m s . v 12 i 12.37865$

E-ISSN: 2091-0576

P-ISSN: 2467-9100

Copyright (c) 2021 Asian Journal of Medical Sciences

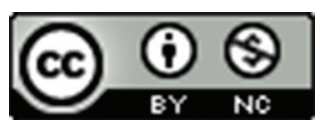

This work is licensed under a Creative Commons Attribution-NonCommercial 4.0 International License.

\section{INTRODUCTION}

If the women have been pregnant more than 4 times, are fewer than 18 or over 35-years-old, or has at least one medical issue before or during pregnancy, the pregnancy is considered high-risk. Increased maternal and fetal mortality and morbidity are linked to these risk factors. ${ }^{1}$ Prenatal and postpartum care, contraception, and abortion are all essential reproductive health interventions for women at high risk of maternal morbidity and mortality. However, obstacles such as restrictive state law and a lack of qualified providers must be overcome. ${ }^{2}$

According to the World Health Organization (WHO), 830 women die every day as a result of problems during pregnancy or childbirth. High-risk pregnancy (HRP) is more common in some countries. ${ }^{3}$

The nationwide rate for unmet need, according to the National Family Health Survey-3 (NFHS-3) 3, is 13\%. According to the District Level Household and Facility Survey-3 (DLHS-3) 4, India has a 21.3\% unmet

\section{Address for Correspondence:}

Dr. Deepali Shrivastava, I/C post partum Unit, Department of Obstetrics and Gynaecology, King George's Medical University, Lucknow,

Uttar Pradesh, India. Mobile: +91-9415320202. E-mail: deepalishrivastava78@gmail.com 
contraceptive requirement, with $7.9 \%$ for spacing and $13.4 \%$ for limiting. ${ }^{4}$ NFHS-4 stated high unmet need for Family planning among married women in U.P. ${ }^{5}$

High-risk mothers contribute for $70-80 \%$ of perinatal death and morbidity, despite accounting for just $10-30 \%$ of all mothers examined during the antenatal period. ${ }^{6}$ Nearly 529000 women die every year in the world as a result of pregnancyrelated conditions. Nearly 118 women are killed or suffer severe acute morbidity for every death. ${ }^{7}$ Early identification and very intensive treatment for high-risk pregnancies can have a major impact on perinatal outcomes. As a result, all pregnancies should be assessed to see whether or not risk factors exist or will exist. ${ }^{8}$ Age, parity, and social status are all factors to consider. Mothers with a history of chronic disease (diabetes, hypertension, heart disease, etc.) or past pregnancy issues (abortion and stillbirth) as well as multiple pregnancies, gestational age under 18 or over 35 years, and pregnancy more than four times are all factors to consider when calculating the risk of any pregnant woman. ${ }^{9}$ HRP may cause prenatal problems (e.g., fetal death) in addition to maternal death. 1 Despite the evident need for improved care and awareness of the hazards, some women chose to become pregnant on their own volition. They remained determined to do so, employing numerous techniques to boost their chances of becoming pregnant and hoping for a healthy kid. Pregnant women may take efforts to protect their own and their fetuses' health, but this does not always imply that they are following medical advice. ${ }^{10}$ Several studies have looked at the effects of mother education on pregnancy difficulties and the risk factors that go along with them. ${ }^{11-13}$

MTP or abortion laws have been liberalized over the world during the past few decades. Abortion has been legal in India since 1972 to lessen the maternal morbidity and death associated with illicit abortions. ${ }^{14}$ It is necessary to promote the use of contraceptive techniques in order to reduce the number of abortions, some of which are high-risk and dangerous. Most countries have moderate to high abortion rates, owing to poorer contraceptive use prevalence and efficacy. ${ }^{15}$ Unfortunately, abortion has become a popular means of restricting and spacing births, but it should never be advocated as a means of family planning. ${ }^{16}$

Between 2015 and 2019, 73.3 million induced (safe and unsafe) abortions were performed annually on a global scale. ${ }^{17}$ Induced abortions were reported to be $39 / 1000$ women aged 15-49. Induced abortions occurred in 3 out of $10(29 \%)$ of all pregnancies and 6 out of $10(61 \%)$ of all unwanted pregnancies. ${ }^{17}$

A high risk pregnancies have a high adverse maternal fetal outcome scoring system was proposed by Coopland et al., ${ }^{18} \mathrm{HRP}$ includes the following factors such as - Age at delivery $<19,>30$ yrs, grand multipara, heart disease, hypertension disorder, ch HT, anemia, rheumatic heart disease (RHD), diabetes mellitus (DM), HIV, AIDS malignancies, previous Cesarean Section, multiple pregnancies, and congenital uterine malformation. ${ }^{18}$

According to the WHO any woman who is pregnant and cannot have a safe abortion is at risk or complications of having an unsafe abortion may suffer a variety of consequences that affect their quality of life and well-being, with some facing life-threatening problems. Hemorrhage, infection, and harm to the vaginal tract and internal organs are the most serious life-threatening complications associated with the least safe abortions. ${ }^{3}$ Despite the fact that many studies have been conducted to assess the prevalence of HRP in India, there have been fewer studies conducted to establish the outcomes of HRP in different parts of India. ${ }^{19}$ In our present study, we included the study of MTP on HRP is done by supervised and skilled personnel.

\section{Aims and objectives}

Aim of the study was intended to calculate the number of women with HRP undergoing MTP, to study the risk factors involved in these women, to study the method used for termination of pregnancy and to study the end result after the procedure and safety of MTP in high-risk pregnancies. Both the methods of MTP surgical and medical have been used for the patients in this study. MTP in various high risk factors has been observed for various parameters.

\section{MATERIALS AND METHODS}

The present observational study was done in the Department of Obstetrics and Gynaecology King George's Medical College, Lucknow UP, India, from the study period from Jan 2018 to Dec 2018. Total admitted patients seeking MTP were 450 out of which 93 participants were enrolled in this study after taking written informed consent form, in the number of MTP's done during this period; women were identified for high-risk factors present. Termination of pregnancy was done after proper consent and as per GOI guidelines either surgical/medical. Out of 93 HRP for termination 88 were first-trimester abortion and 5 cases were of $2^{\text {nd }}$ trimester abortion. MTP of the entire participant was terminated by medical and surgical method, seven cases were terminated by medical method, and 86 cases were done by surgical method.

\section{Medical method}

Mifestrone $200 \mathrm{mg}$ F/B misoprostol $400 \mathrm{mg}$ BD given after up to 489 (Sublingual), Mifesterone $200 \mathrm{mg}$ followed by 
misoprostol $200 \mathrm{mg} 4 \mathrm{mg}$ after $48 \mathrm{~h}$ in second trimester (Per vaginal).

\section{Surgical method}

Section evacuation done $4 \mathrm{~m}$ sedation and local anesthesia and followed by per vaginal misoprostol given per vaginal for 2 weeks prior to surgery.

\section{Inclusion and exclusion criteria}

All patients who fulfill indications of MTP and $<20$ weeks of pregnancy were included in study cases unwilling to sign informed consent were excluded from the study.

\section{Investigations and data collection}

Records of PP unit of QMH from Jan 2018 to Dec 2018 were utilized to provide data for this observational study. Subjects were investigated for Hemoglobin, Viral Marker, Blood group ( $\mathrm{ABO}$ and $\mathrm{RH}$ ), blotting time, clotting time, and Ultrasound done according to need for relevant medical illnesses as required.

\section{Statistical analysis}

For continuous data, normality was tested using the Kolmogorov Smirnov test. For non-normal continuous data, the Kruskal Wallis $\mathrm{H}$ test was used to compare the groups as appropriate. Categorical data were presented in frequency and percentage. Statistical analysis was carried out using the statistical package for social science, version 22 (SPSS-22, IBM, Chicago, USA). Two-tailed $\mathrm{P}<0.05$ has been considered as statistically significant.

\section{RESULTS}

In this present study, Table 1 showing that the majority of women $(76.344 \%)$ pregnant were age of 35 years and above, $13.979 \%$ were $30-34$ years, $2.150 \%$ were teenagers pregnancy, $60.439 \%$ women were multipapa (were 37.634\% having two children and $21.506 \%$ having three child), $22.580 \%$ women were grand multipara (4 or more). Table 1 also shows that interval MTP since last delivery were the majority $(32.258 \%$ ) of women having $2-5$ years and less women $(15.053 \%)$ were less than and equal to 1 year.

Distribution of women according to obstetrics and medical risk factor (Table 2) $71 \%$ women having age 35 years or above, 58\% were multipara, 21\% women were grand multipara, 17 women $(18.279 \%)$ previous lower segment caesarian section (LSCS) and 10 (10.752\%) RHD and 4 (4.301\%) malignancy and Diabetes Mellitus respectively, 1 (1.075) women were and chronic kidney disease, CVA, chronic liver diseases and hypertension respectively, i.e., medical disorder contributed 18.279\% in this study.
Contraceptive acceptance by women undergoes MTP was given in Table $340 \%$ of women accepted IUCD, 30\% underwent sterilization, $1.075 \%$ of women had chosen barrier method for contraception, OCP's, and injectable contraception, rest had not taken any contraception after MTP (Table 3).

Complications of HRP after MTP were shown in Figure 1, $79.569 \%$ of women has no complications after MTP, $12.903 \%$ of women had mild and moderate pain in the abdomen, $5.376 \%$ of women has vaginal bleeding complain and less approximately $2.150 \%$ of women has complained of nausea and vomiting.

\begin{tabular}{|c|c|c|c|}
\hline Parameters & Risk factor & $\begin{array}{c}\text { Number of } \\
\text { women }(n=93)\end{array}$ & Percentage \\
\hline \multirow[t]{5}{*}{ Age } & $<19$ years & 2 & 2.150 \\
\hline & $20-24$ years & 3 & 3.225 \\
\hline & $25-29$ years & 4 & 4.301 \\
\hline & 30-34 years & 13 & 13.979 \\
\hline & 35 yrs or above & 71 & 76.344 \\
\hline \multirow[t]{5}{*}{ Parity } & $\mathrm{PO}$ & 5 & 5.376 \\
\hline & P1 & 12 & 12.903 \\
\hline & P2 & 35 & 37.634 \\
\hline & P3 & 20 & 21.505 \\
\hline & P4 or more & 21 & 22.580 \\
\hline \multirow{4}{*}{$\begin{array}{l}\text { Interval } \\
\text { since last } \\
\text { delivery }\end{array}$} & $\leq 1$ year & 13 & 13.978 \\
\hline & $2-5$ years & 30 & 33.333 \\
\hline & $5-9$ years & 28 & 22.580 \\
\hline & $\geq 10$ years & 22 & 23.655 \\
\hline
\end{tabular}

Table 2: Distribution of high risk pregnancies by high risk of obstetrical and medical factors

\begin{tabular}{lcc}
\hline Risk factors & Number of women & Percentage \\
\hline Age>35 years & 71 & 61.290 \\
Multipara & 55 & 54.838 \\
Grand multipara & 21 & 22.580 \\
RHD & 5 & 5.376 \\
Previous LSCS & 17 & 18.279 \\
Chronic kidney disease & 1 & 1.075 \\
Malignancy & 4 & 4.301 \\
CVA & 1 & 1.075 \\
Chronic liver disease & 1 & 1.075 \\
Diabetes mellitus & 4 & 4.301 \\
Hypertension & 1 & 1.075
\end{tabular}

\begin{tabular}{lcc}
$\begin{array}{l}\text { Table 3: Distribution of method of contraception } \\
\text { post MTP }\end{array}$ & \\
\hline Method of contraception & Number of women & Percentage \\
\hline None & 20 & 21.505 \\
Barrier contraceptives & 1 & 1.075 \\
OCP's & 1 & 1.075 \\
Injectable contraceptives & 1 & 1.075 \\
Copper T & 40 & 43.010 \\
Lap ligation & 30 & 32.259 \\
\hline
\end{tabular}




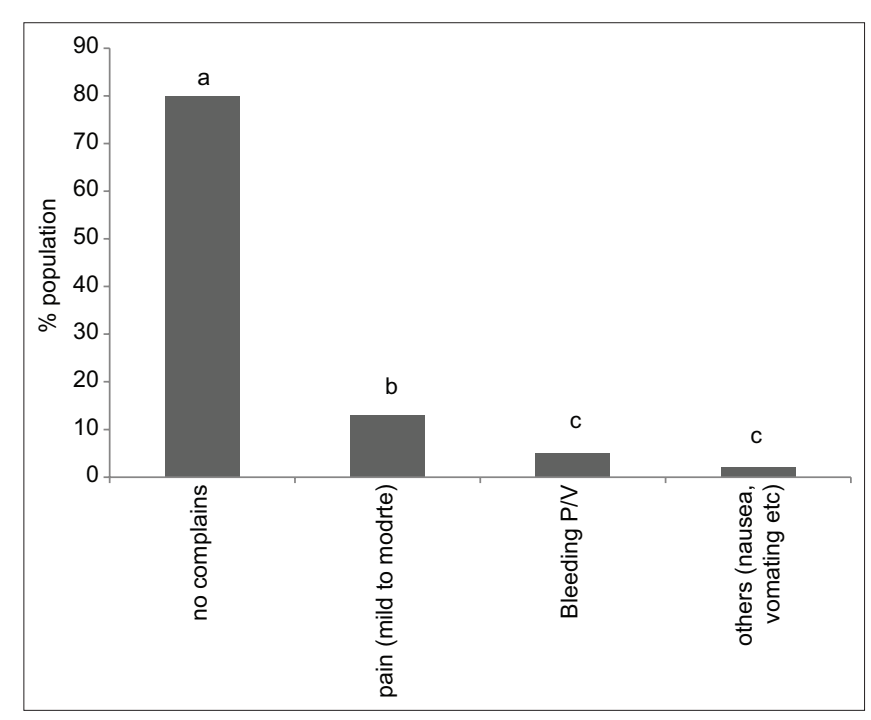

Figure 1: Complications of high risk pregnancy after MTP; different alphabets shows significant variation between groups; Kruskal-Wallis $\mathrm{H}$ test was used to calculate significance level at $\mathrm{P}<0.05$

\section{DISCUSSION}

This study basically involved the women belonging to high risk pregnant females in reproductive age group seeking MTP for various indications falling in to guidelines laid by GOI which includes the continuation of pregnancy that would involve a risk to the life of pregnant women or of grave injury to her physical or mental health.

Results show that incidence of HRP for MTP in our hospital group is about 20.6 and they all need extra measures and care during and after MTP because of their risk factors like they require extra check-up and supervision for antenatal and post-natal period.

Amongst all risk factors, Maximum number $76.344 \%$ women were of elderly age group, 35 years or more. Next to this $37.634 \%$ of women having two kids reflected the large unmet need of contraception in our study. Patients with medical disorders contributed to $18.279 \%$.This shows that there are still large unmet needs of contraception. In another study conducted in Egypt, the majority of the participants $(44 \%)$ were between the ages of 30 to 35 years. $^{7}$ HRP includes following factors like - Age at delivery $<19$, $>30$ yrs, Grand multipara, Heart disease, hypertension disorder, ch HT, anemia, RHD, DM, HIV, AIDS malignancies, previous Cesarean Section, multiple pregnancies, and congenital uterine malformation. ${ }^{18}$ In a previous study the prevalence of HRP was higher i.e., $77 \%$ in multigravida compared to primigravida $(23 \%) .{ }^{20}$ Our present study shows higher multiparous $(53.838 \%$ ) as compared to primiparous $(12.903 \%)$. Previous study also shows higher multiparous as compared to primiparous. HRP was found to be linked to parity and socioeconomic status independently In a research conducted in Karnataka, similar results were found. ${ }^{21}$ Another study in Rohtak, Haryana, India, revealed that $13.7 \%$ of grand multigravida (four and above) women had high risk. ${ }^{8}$

Patients with medical disorders like RHD, chronic heart disease malignancy, CVA, chronic liver disease, DM and hypertension contributed to $18.682 \%$ in this study. High blood pressure, gestational diabetes, and delivery difficulties are all more common in women over $35 .{ }^{22}$ When a woman has experienced a difficulty during one pregnancy, such as preterm birth, a baby with birth abnormalities, previous abortion, past stillbirth, or a previous caesarean section, she is more likely to experience the same problem with subsequent pregnancies. ${ }^{23-26}$ Hypertension was found in $22 \%$ of high-risk pregnancies, according to a previous study. ${ }^{8}$ A previous study done in Nagpur also revealed that HRP had significant association with LSCS, which is contrast to our current study $18.279 \%$ women were previous LSCS. ${ }^{19}$

A large number of women had a long inter delivery interval. In this study, number of $30.107 \%$ women had 5-9 years of interval since their last delivery. $23.655 \%$ were 10 years and above. Patients of these groups require extra care and precautions advised from specialists so complications and post procedure problems were minimal because of these measures taken all the patients were given contraception according to their need and health issues. NFHS-4 stated high unmet need for Family planning among married women in U.P. Unmet needs are found quite high in my studies also. Total unmet need has 12.1 and for spacing has $5.1,5$ which could not be calculated in our study because we have taken patients with contraceptive failure and only high risk groups. Previously there was a 27.3\% unmet need for contraceptives. There was a $4.9 \%$ and $22.5 \%$ unmet requirement for spacing and restricting, respectively. Clientrelated reasons were cited by $50 \%$ of those with unmet need $(\mathrm{n}=73)$, while contraception-related factors were cited by $37 \%$ (availability, accessibility, affordability, side effects). ${ }^{27}$

\section{Limitations of the study}

We were unable to collect information on a variety of potential risk variables for HRP, including education, employment status, spousal support, age at marriage, and age at first pregnancy. Due to the inability to extract data on time of exposure from case records, causal results for factors connected to HRP and outcomes cannot be deduced. More studies need to be done to focus on factors that influence HRP and pregnancy outcomes.

\section{CONCLUSION}

We concluded that the major cause of HRP is related to maternal age and multipara with. Similarly pregnancy with 
RHD, chronic kidney disease, previous LSCS, malignancies, D.M, other medical disorders has serious fetoe-maternal outcomes so if indicated safe abortions are life saving for these women and they can help in reducing maternal mortality as well as in decreasing Infant mortality rate. A large number of high-risk groups for MTP again showing the unmet need and lack of specialized counseling of HR patients according to their mental and physical condition. Early recognition of pregnancy and timely intervention can be lifesaving in these women and proper contraceptive counseling is required to prevent future pregnancies. This present study is showing the only tip of the iceberg of the problem. A lot more awareness is required and postnatal contraception is a must. MTP is a nightmare in some medical disorders and they are being refused at early pregnancy when it is safer than performing in late or advanced pregnancy or if they continue the pregnancy. So providing them safe supervised abortion services to be considered over just refusing safe abortion services merely because of high risk factors.

\section{ACKNOWLEDGMENT}

We would like to express our gratitude to all of the participants for their participation and support, without which this study would not have been possible. Also thanks to the staff of primary healthcare of the Obstetrics and Gynaecology Department, KGMU, Lucknow, India.

\section{REFERENCES}

1. Berek JS. Berk and Novak Gynecology. $15^{\text {th }}$ ed. Philadelphia, PA: Lippincott Williams and Wilkins; 2012.

2. Jones RK, Witwer $E$ and Jerman J. Abortion Incidence and Service Availability in the United States, 2017. New York: Guttmacher Institute; 2019.

https://doi.org/10.1363/2019.30760

3. World Health Organization. Maternal Mortality. Geneva: World Health Organization; 2019.

4. District Level Household and Facility Survey III 200708 (DLHS III). Ministry of Health and Family Welfare, Government of India; 2008. Available from: https://main. mohfw.gov.in/sites/default/files/DLHS\%20III.pdf [Last assessed on 2013 Oct 29].

5. Yadav K, Agarwal M, Shukla M, Singh JV and Singh VK. Unmet need for family planning services among young married women (15-24years) living in urban slums of India. BMC Womens Health. 2020;20(1):187.

https://doi.org/10.1186/s12905-020-01010-9

6. Pradeep MK, Gnanadeep NV, Umesh RD and Pushpa SP. Prevalence of high risk pregnancy in rural Dharwad. IOSR J Dent Med Sci. 2015;14(10):29-32.

7. Samar KH, Dorgham LS and Suheir AM. Profile of high risk pregnancy among Saudi women in Taif-KSA. World J Med Sci. 2014;11(1):90-97.

8. Vijay KB, Amandeep K, Sumit C and Manisha M. Prevalence and correlates of high risk pregnancy in rural Haryana: A community based study. IJBAMS. 2013;3(2):212-217.

9. Firozi S. The rate of the prevalence of high-risk pregnancy and the results on pregnant mothers and the effect on parameters after the birth. IJPSR. 2012;3(10):3735-3741.

10. Lee $S$, Ayers $S$ and Holden D. A meta-synthesis of risk perception in women with high risk pregnancies. Midwifery. 2014;30(4):403-411.

https://doi.org/10.1016/j.midw.2013.04.010

11. Otaiby TA, Jradi $H$ and Bawazir A. Antenatal education: An assessment of pregnant women knowledge and preferences in Saudi Arabia. J Womens Health Care. 2013;2(4):1-5.

https://doi.org/10.4172/2167-0420.1000139

12. Okeh NO, Hawkins KC, Butler W and Younis A. Knowledge and perception of risks and complications of maternal obesity during pregnancy. Gynecol Obstet. 2015;5(9):1-5.

https://doi.org/10.4172/2161-0932.1000323

13. Esposito G, Ambrosio R, Napolitano F and di Giuseppe G. Women's knowledge, attitudes andbehavior about maternal risk factors in pregnancy. PLoS One. 2015;10(12):e0145873.

https://doi.org/10.1371/journal.pone.0145873

14. Manual for First Trimester MTP. Technical Operations Division, Ministry of Health and Family Welfare, Government of India, Nirman Bhavan, New Delhi; 2003. p. 11.

15. Henshaw SK, Singh $S$ and Hass T. The incidence of abortion worldwide. Int Fam Plann Persp. 1999;25:S30-S38.

16. Guillaumc A. Abortion in Africa. A Birth Control Method and a Public Health Issue. France: CEPED, NPWE; 2000. p. 1.

17. Bearak J, Popinchalk A, Ganatra B, Moller AB, Tunçalp Ö, Beavin $C$, et al. Unintended pregnancy and abortion by income, region, and the legal status of abortion: Estimates from a comprehensive model for 1990-2019. Lancet Glob Health. 2020;8(9):e1152-e1161.

https://doi.org/10.1016/s2214-109x(20)30315-6

18. Coopland AT, Peddle LJ and Baskett TF. A Simplified antepartum high risk pregnancy scoring form: Statistical analysis of 5459 cases. CMA J. 1997;116(9):999-1011. https://doi.org/10.1097/00006254-197711000-00014

19. Jadhao AR, Gawade MD and Ughade SN. Outcome of pregnancy among high risk pregnancies in rural area of Nagpur, Maharashtra, Central India. Int J Community Med Public Health. 2017;4:628-633.

https://doi.org/10.18203/2394-6040.ijcmph20170443

20. Jaideep KC, Prashant D and Girija A. Prevalence of high risk among pregnant women attending antenatal clinic in rural field practice area of Jawaharlal Nehru Medical College, Belgavi, Karnataka, India. Int J Community Med Public Health. 2017;4(4):1257-1259.

https://doi.org/10.18203/2394-6040.ijcmph20171359

21. Majella MG, Sarveswaran G, Krishnamoorthy Y, Sivaranjini K, Arikrishnan $\mathrm{K}$ and Kumar SG. A longitudinal study on high risk pregnancy and its outcome among antenatal women attending rural primary health Centre in Puducherry, South India. J Educ Health Promot. 2019;8:12.

22. Merck. Risk factors present before pregnancy. In: Merck Manual Home Health Handbook. New Jersey, United States: Merck Sharp and Dohme.; 2010.

23. Arias F. Practical Guide to High Risk Pregnancy and Delivery. $2^{\text {nd }}$ ed. United States: Mosby Inc.; 1993

24. Arulkumaran S, Ratnam SS and Rao KB. The Management of Labor. Chennai, India: Orient Longman Limited; 1996.

25. Beers MH and Berkow R. The Merck's Manual of Diagnosis and Therapy. $18^{\text {th }}$ ed. United States: Merck and Co.; 2006. 
26. Krishna U, Tank DK and Daftary S. Pregnancy at Risk: Current Concepts. $4^{\text {th }}$ ed. New Delhi: Jaypee Brothers Pvt. Ltd.; 2001.

27. Sulthana B, Shewade HD, Sunderamurthy B, Manoharan K and
Subramanian M. Unmet need for contraception among married women in an urban area of Puducherry, India. Indian J Med Res. 2015;141(1):115-118.

https://doi.org/10.4103/0971-5916.154513

\section{Authors Contribution:}

DS- Concept and design of the study; prepared first draft of manuscript, Interpreted the results; reviewed the literature and manuscript preparation;

SS- Concept, coordination, review of literature and manuscript preparation; PK- Statistically analysed and interpreted, preparation of manuscript and revision of the manuscript; DS- Preparation of manuscript and revision of the manuscript.

\section{Work attributed to:}

King George's Medical University, Lucknow, Uttar Pradesh, India.

Orcid ID:

Dr. Deepali Srivastava - (1) https://orcid.org/0000-0003-4843-1742

Dr. Sandeepa Srivastava - (1) https://orcid.org/0000-0002-7143-6026

Dr. Pratibha Kumari - (D) https://orcid.org/0000-0002-9622-4695 